\title{
FAKTOR TEKNIS YANG BERPENGARUH TERHADAP HASIL TANGKAPAN UTAMA PUKAT UDANG DI LAUT ARAFURA
}

\section{TECHNICAL FACTORS THAT INFLUENCE THE MAIN SHRIMP TRAWL CATCHES IN THE ARAFURA SEA}

\author{
Daniel Rezki ${ }^{1}$, Ronny I Wahju ${ }^{2}$, Mulyono S Baskoro ${ }^{2}$, Muhammad Imron ${ }^{2}$ \\ ${ }^{1}$ Program Studi Teknologi Perikanan Laut, Sekolah Pascasarjana \\ ${ }^{2}$ Departemen Pemanfaatan Sumberdaya Perikanan \\ Fakultas Perikanan dan Ilmu Kelautan, Institut Pertanian Bogor \\ Korespondensi : daniel_rezki@yahoo.com
}

\begin{abstract}
Shrimp is an economic important commodity in fishery with shrimp trawl as the most effective fishing gear. One of effort to maximize the number of shrimp catch is the application of the technical factors which significantly influence the catch rate of shrimp. Method of this research was observational. The purpose of this research was to analyze the influence of fishing time (day and night), towing speed, and towing duration towards shrimp catch rate. The result of this research are night operation has greater catch rate $(24.10 \pm 9.60 \mathrm{~kg} / \mathrm{hour}$, the effective tow duration is $91-150$ minutes $(46.78 \pm 22 \mathrm{~kg} / \mathrm{hauling})$ and towing speed with greater catch rate is $2.50-3.00 \mathrm{knot}(13.18 \pm 3.30 \mathrm{~kg} / \mathrm{hour})$. The results of the analysis should that factors can maximize the catch of shrimp trawl.
\end{abstract}

Keywords: technical aspect, catch rate, shrimp trawl, towing

\begin{abstract}
ABSTRAK
Udang merupakan komoditas perikanan ekonomis penting dengan alat tangkap yang paling efektif yakni pukat udang. Salah satu upaya untuk memaksimalkan jumlah tangkapan udang adalah dengan mengetahui faktor teknis yang signifikan terhadap laju tangkap udang. Tujuan dari penelitian ini adalah menganalisis faktor teknis operasi penangkapan yang dapat memaksimalkan laju tangkap pukat udang. Faktor teknis yang dianalisis adalah waktu penangkapan (siang dan malam), kecepatan towing dan lama towing terhadap laju tangkap pukat udang. Metode penelitian yang digunakan pada penelitian ini adalah observasi. Hasil dari penelitian ini adalah laju tangkap pada malam hari lebih tinggi (24.10 $\pm 9.60 \mathrm{~kg} / \mathrm{jam})$, lama towing efektif yakni $91-150$ menit $(46.78 \pm 22 \mathrm{~kg} / \mathrm{hauling})$ dan kecepatan towing dengan laju tangkap yang lebih tinggi yakni 2.50-3.0 0knot (13.18 $\pm 3.330 \mathrm{~kg} /$ hour). Hasil analisis menyatakan faktor-faktor dapat memaksimalkan hasil tangkapan pukat udang.
\end{abstract}

Kata kunci: faktor teknis, laju tangkap, pukat udang, towing

\section{PENDAHULUAN}

Udang merupakan komoditas perikanan yang memiliki potensi besar karena merupakan produk ekspor dengan nilai jual yang tinggi. Berdasarkan Statistik Kelautan dan Perikanan (2011), nilai produksiudang tangkapan di laut pada tahun 2011 mencapai Rp 7.308.097.682.000, 00. Harga udang tiger (Penaeus semisulcatus) di pasaran mencapai 130 ton/tahun. Oleh karena nilai jual yang tinggi maka banyak perusahaan penangkap udang yang berupaya menangkap dan mengekspor komoditi ini.

Alat tangkap yang paling efektif untuk menangkap udang adalah pukat udang. Perikanan pukat udang di Indonesia umumnya berskala industri. Perusahaan pukat udang biasanya melakukan operasi penangkapan di Laut Arafura karena potensinya yang besar. Berdasarkan Statistik Kelautan dan Perikanan (2011), potensi udang penaeidae di Arafura sebesar 44.700 ton/tahun namun hasil tangkapannya fluktuatif dan cenderung menurun. Beberapa tahun belakangan beberapa perusahaan pukat udang mengalami kesulitan sehingga tidak aktif lagi (Sumiono et al. 2011). Oleh karena itu, dibutuhkan beberapa upaya untuk mengatasi permasalahan tersebut dan salah satunya adalah efektivitas operasi penangkapan agar hasil tangkapan 
maksimal.

Tujuan dari penelitian ini adalah menganalisis pengaruh faktor teknis operasi penangkapan seperti waktu penangkapan, lama towing, dan kecepatan towing terhadap jumlah tangkapan pukat udang. Faktor tersebut merupakan faktor yang mudah untuk diterapkan oleh nelayan sehingga diharapkan hasil penelitian ini aplikatif.

\section{METODE PENELITIAN}

Data yang dianalisis dalam penelitian ini di peroleh dari hasil observasi dengan cara mengikuti kegiatan operasi penangkapan udang pada Juli-Agustus 2013 di Laut Arafura.

Data yang dikumpulkan adalah waktu pengoperasian, kecepatan towing, dan lama towing serta hasil tangkapan. Data tersebut juga digabungkan dengan data jurnal penangkapan pukat udang Sekolah Tinggi Perikanan Jakarta. Pengumpulan dan penggabungan data ini bertujuan menganalisis faktor penangkapan yang tidak hanya pada waktu atau bulan tertentu, maka diperlukan data yang lebih komprehensif sehingga hasil analisis dapat diterapkan dengan maksimal.

Data yang telah dikumpulkan selanjutnya di tabulasi dan dikelompokkan ke dalam kisaran tertentu. Data hasil tangkapan yang didapat terlebih dahulu dianalisis kenormalannya dengan menggunakan uji Kolmogorof-Smirnov. Faktor teknis yang dianalisis adalah waktu penangkapan (siang dan malam), kecepatan towing, lama towing terhadap laju tangkap udang. Penelitian ini bukanlah penelitian dengan rancangan percobaan, sehingga ulangan tiap perlakuan pada tiap faktor tidak sama.

Data yang terdistribusi normal adalah hasil tangkapan dengan perbedaan waktu penangkapan dan lama towing. Pengaruh waktu pengangkapan terhadap laju tangkap mengunakan uji-t, sedangkan lama towing menggunakan uji ANOVA yang dilanjutkan dengan uji Scheffe. Data laju tangkap berdasarkan kecepatan towing dan kedalaman perairan tidak menyebar normal sehingga digunakan uji non parametrik Kruskal-Wallis yang dilanjutkan dengan uji Games-Howell. Hipotesis penelitian ini yakni, $\mathrm{HO}=$ perlakuan tidak berpengaruh terhadap laju tangkap udang dan $\mathrm{H} 1$ = minimal ada satu perlakuan yang berpengaruh terhadap laju tangkap udang. Analisis pada penelitian ini menggunakan software SPSS 16.0.

\section{HASIL DAN PEMBAHASAN}

\section{Pengaruh waktu penangkapan (siang dan malam) terhadap laju tangkap udang}

Waktu operasi pada pukat udang di Arafura yakni 24 jam. ABK kapal dibagi menjadi dua kelompok yang akan bergantian shift kerja dengan durasi delapan jam. Operasi penangkapan dilakukan baik siang maupun malam apabila kondisi memungkinkan.

Data yang didapatkan diuji normalitasnya dengan uji KolmogorovSmirnov dengan hasil data terdistribusi normal $(P=0.37>0.05)$. Uji-t untuk laju tangkap berdasarkan waktu penangkapan signifikan $(\mathrm{P}=0.48>0.05)$, yang berarti waktu penangkapan mempengaruhi laju tangkap udang. Laju tangkap tiap jenis udang berdasarkan waktu penangkapan dapat dilihat pada Tabel 1 .

Laju tangkap udang pada malam hari lebih tinggi yakni $24.10 \pm 9.60 \mathrm{~kg} / \mathrm{jam}$, Sedangkan siang hari lebih rendah yakni $15.30 \pm 7.60 \mathrm{~kg} / \mathrm{jam}$ (Gambar 1). Perbedaan laju tangkap untuk tiap jenis udang pada siang dan malam hari dapat dilihat pada Gambar 2.

Hasil tangkapan pukat udang didominasi oleh 3 jenis udang yaitu udang tiger (Penaeus semisulcatus), Ende blue (Metapenaeus endeavouri) dan Ende pink (Metapenaeus monoceros). Gambar 2 menunjukkan bahwa ketiga jenis udang ini yang paling ekstrim perbedaan laju tangkap antara siang dan malam hari. Laju tangkap udang tiger pada malam hari $14.32 \mathrm{~kg} /$ jam, sedangkan siang $5.36 \mathrm{~kg} / \mathrm{jam}$. Udang Ende blue (Metapenaeus endeavouri) malam hari $1.04 \mathrm{~kg} / \mathrm{jam}$, siang hari $4.79 \mathrm{~kg} /$ jam, sedangkan Ende pink (Metapenaeus monoceros) malam hari $2.88 \mathrm{~kg} / \mathrm{jam}$ sedangkan siang hari $1.36 \mathrm{~kg} / \mathrm{jam}$.

Bishop (2008) menyatakan bahwa udang penaeidae memiliki tingkah laku menguburkan diri pada waktu siang hari. Tingkah laku mengubur diri tersebut berguna untuk menyimpan energi dan juga upaya untuk menghindari predator (Dall et al. 1990). Namun untuk udang yang berukuran kecil (juvenile) dan udang yang berada pada daerah yang lebih dangkal di sekitar muara sungai, tidak menguburkan diri pada siang hari (Simoes et al. 2010)

Penangkapan udang lebih baik 
dilakukan pada malam hari agar maksimal karena pada siang hari udang menguburkan diri. Perilaku udang mengubur diri dan pasif tersebut menyebabkan udang lebih sedikit tertangkap. Udang berada di atas substrat pada malam hari sehingga pukat udang akan lebih efektif menangkap udang pada saat rantai pengejut menyapu permukaan substrat.

Jenis udang yang secara statistik berbeda nyata laju tangkapnya antara siang dan malam hari adalah udang dengan panjang karapas pada hasil observasi lebih besar yakni udang tiger (Penaeus semisulcatus) 7.00-9.00 cm, Ende blue (Metapenaeusend eavouri) 5.70-6.70 cm, Ende pink (Metapenaeus monoceros) 5.70$6.70 \mathrm{~cm}$, banana (Penaeus merguiensis) 7.00-8.00 cm, Kiji (Metapenaeopsis eboracensis) $5.00-5.30 \mathrm{~cm}$, uchiwa (Thenus orientalis) 6.60-7.60 cm, king (Penaeus lattisulcatus) $5.60-6.60 \mathrm{~cm}$ dan black tiger (Penaeus monodon) $11.50-12.50 \mathrm{~cm}$. Hal ini diduga karena ukuran dari jenis udang tersebut lebih besar dibandingkan dengan udang kerosok (Parapenaeopsis sculptilis) dan Red (Metapenaeu sensis) dengan panjang karapaks masing-masing 3.80-4.10 $\mathrm{cm}$ dan dan 4.70-5.00 cm. Udang-udang yang signifikan diduga dapat mengubur diri lebih dalam dan tidak tersapu oleh rantai pengejut. Sesuai dengan hasil penelitian Simoes et al. (2010) yakni tidak terdapat perbedaan yang nyata antara jumlah udang yang berukuran kecil dengan perbedaan waktu penangkapan siang dan malam hari.

Tabel 1. Laju tangkap pukat udang pada siang dan malam hari

\begin{tabular}{ccclccc}
\hline \multirow{2}{*}{ Nama Lokal } & \multicolumn{2}{c}{ Hasil tangkapan (kg) } & \multirow{2}{*}{ Jumlah } & \multicolumn{2}{c}{ Laju tangkap (kg/hauling) } \\
\cline { 2 - 4 } & Siang & Malam & & Siang & Malam \\
\hline Tiger & 1440.57 & 3729.28 & 5169.85 & $7.31 \mathrm{a}$ & $13.86 \mathrm{~b}$ \\
Banana & 62.45 & 46.29 & 108.74 & $0.32 \mathrm{a}$ & $0.17 \mathrm{~b}$ \\
Ende pink & 434.18 & 766.40 & 1200.58 & $2.20 \mathrm{a}$ & $2.85 \mathrm{~b}$ \\
Ende blue & 457.91 & 1283.03 & 1740.94 & $2.32 \mathrm{a}$ & $4.77 \mathrm{~b}$ \\
Uchiwa & 36.96 & 138.82 & 175.79 & $0.19 \mathrm{a}$ & $0.52 \mathrm{~b}$ \\
King & 18.56 & 46.05 & 64.62 & $0.09 \mathrm{a}$ & $0.17 \mathrm{~b}$ \\
Kiji & 392.98 & 287.73 & 680.71 & $1.99 \mathrm{a}$ & $1.07 \mathrm{~b}$ \\
Kerosok & 135.13 & 140.44 & 275.57 & $0.69 \mathrm{a}$ & $0.52 \mathrm{a}$ \\
Red & 32.56 & 48.87 & 81.43 & $0.17 \mathrm{a}$ & $0.18 \mathrm{a}$ \\
B. Tiger & 9.19 & 5.35 & 14.54 & $0.05 \mathrm{a}$ & $0.02 \mathrm{~b}$ \\
\hline Total & 3020.50 & 6492.25 & 9512.76 & $15.33 \mathrm{a}$ & $24.13 \mathrm{~b}$ \\
\hline n setting & 197 & 269 & 466 & & \\
\hline
\end{tabular}

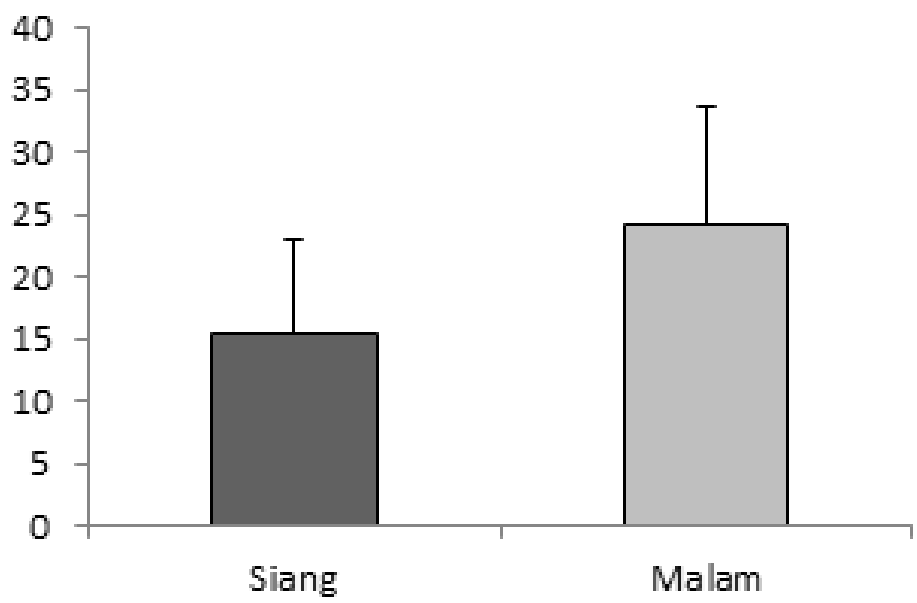

Gambar 1. Laju tangkap udang berdasarkan perbedaan waktu operasi 


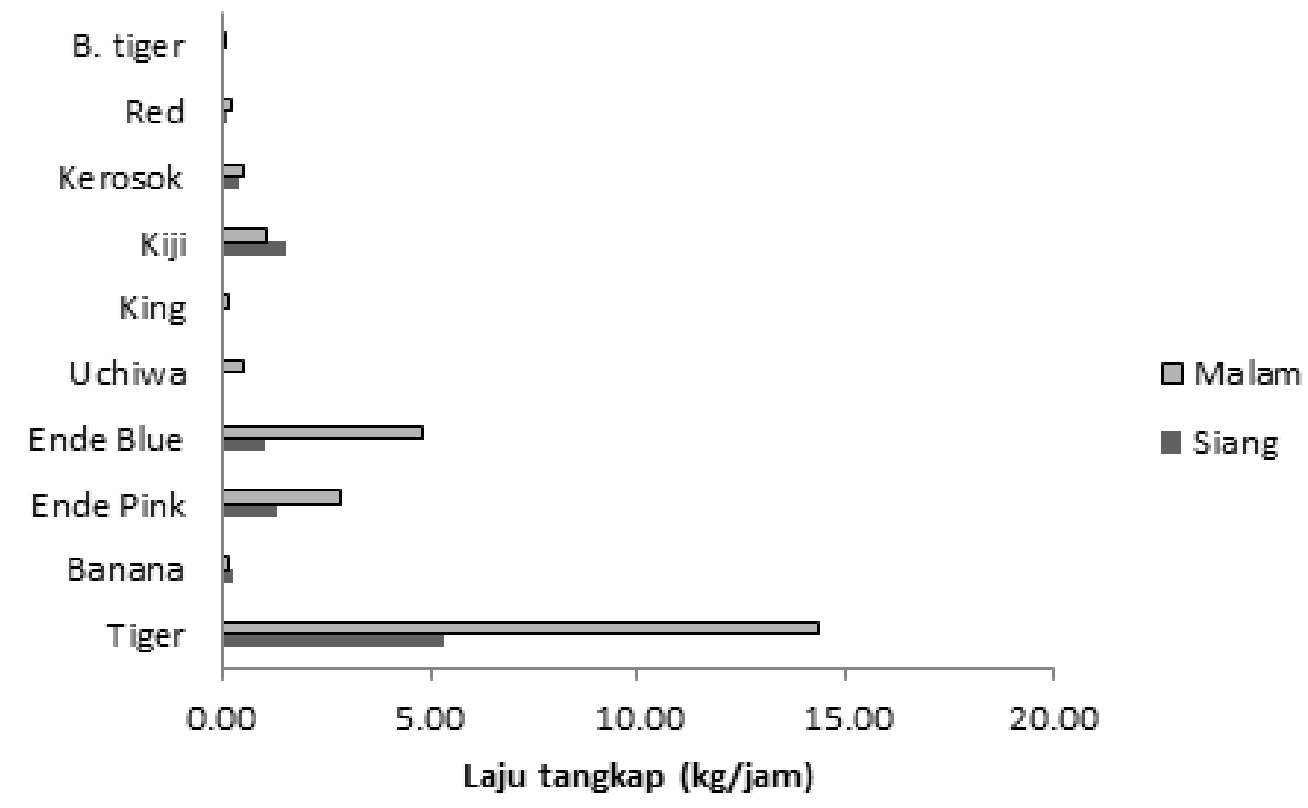

Gambar 2. Perbedaan laju tangkap udang berdasarkan waktu operasi

\section{Pengaruh lama towing (penarikan jaring) terhadap laju tangkap udang}

Pengelompokkan lama towing dimulai dari 30 menit karena pada kondisi sebenarnya nelayan tidak melakukan lama towing dalam kisaran 30 menit pertama karena dinilai terlalu singkat sehingga tangkapan tidak maksimal. Hasil tangkapan udang berdasarkan kisaran lama towing yang berbeda disajikan pada Tabel 2 .

Dalam kisaran lama towing 30 hingga 210 menit, semakin lama durasi towing maka laju tangkap akan semakin tinggi (Gambar 3). Hasil uji ANOVA menunjukkan bahwa ada perbedaan jumlah hasil tangkapan berdasarkan perbedaan lama towing karena nilai signifikansinya lebih kecil dari 0.05 yakni 0.00 .

Jenis udang dominan yang tertangkap dengan lama towing yang berbeda adalah udang tiger (Penaeus semisulcatus), Ende blue (Metapenaeus endeavouri), dan Ende pink (Metapenaeus monoceros). Perbedaan laju tangkap tiap spesies udang dengan perbedaan lama towing dapat dilihat pada Gambar 4. Laju tangkap udang Tiger pada 91-150 dengan 151-210 menit hampir sama (Gambar 4).

Laju tangkap udang Ende pink (Metapenaeus monoceros) semakin tinggi seiring bertambahnya lama towing namun tidak signifikan (Tabel 2). Begitu juga dengan laju tangkap udang Ende blue (Metapenaeus endeavouri) yakni semakin tinggi seiring pertambahan lama towing namun setelah diuji dengan uji lanjut Scheffe lama towing yang signifikan adalah 91-150 menit

Wieland et al. (2006) menguji pengaruh perbedaan lama towing antara 15 dengan 30 menit dan tidak menemukan perbedaan yang nyata walaupun ditemukan hasil tangkapan udang pada 30 menit lebih banyak. Hal tersebut diduga karena perbedaan durasi towing terlalu singkat yakni hanya 15 menit.

Triharyuni \& Trihargiyatno (2012) melakukan penelitian mengenai model produksi jaring arad (mini trawl) dengan salah satu faktor yakni lama towing. Kisaran lama penarikan 75-225 menit dan disimpulkan bahwa lama penarikan jaring memberi pengaruh nyata terhadap jumlah tangkapan.

Berdasarkan uji ANOVA didapat hasil bahwa pada masing-masing selang lama towing yang di uji berpengaruh nyata terhadap jumlah hasil tangkapan udang, namun dari hasil uji lanjut Scheffe, ketika dibandingkan jumlah tangkapan 91150 menit dengan 151-210 menit, tidak ditemukan perbedaan yang signifikan. Oleh karena itu, armada pukat udang disarankan untuk melakukan penangkapan dalam kisaran waktu 91-150 menit. Walaupun pada kisaran 151-210 menit hasil tangkapan lebih banyak namun perbedaannya tidak signifikan. Lama towing 151-210 juga akan memberi dampak terhadap kualitas hasil tangkapan udang yang akan menurun karena terluka akibat jaring maupun tertindih biota lainnya (Gamito \& Cabral 2003). 
Tabel 2. Hasil tangkapan pukat udang dengan lama towing yang berbeda

\begin{tabular}{|c|c|c|c|c|c|c|}
\hline \multirow[b]{2}{*}{ Nama Lokal } & \multicolumn{3}{|c|}{ Hasil tangkapan (kg) } & \multicolumn{3}{|c|}{ Laju tangkap (kg/hauling) } \\
\hline & $\begin{array}{c}30-90 \\
\text { (menit) }\end{array}$ & $\begin{array}{l}\text { 91-150 } \\
\text { (menit) }\end{array}$ & $\begin{array}{c}\text { 151- } \\
210 \\
\text { (menit) }\end{array}$ & $\begin{array}{c}30-90 \\
\text { (menit) }\end{array}$ & $\begin{array}{l}\text { 91-150 } \\
\text { (menit) }\end{array}$ & $\begin{array}{c}151-120 \\
\text { (menit) }\end{array}$ \\
\hline Tiger & 601.00 & 48.00 & 2410.50 & $19.39 a$ & $23.94 b$ & $23.87 b$ \\
\hline Banana & 14.00 & 206.00 & 33.00 & $0.45 a$ & $0.39 a$ & $0.33 a$ \\
\hline Ende pink & 159.50 & 12735.00 & 705.00 & $5.15 \mathrm{a}$ & $6.30 a$ & $6.98 \mathrm{a}$ \\
\hline Ende blue & 143.00 & 3352.00 & 1227.00 & $4.61 \mathrm{a}$ & $9.34 b$ & $12.15 b$ \\
\hline Uchiwa & 18.00 & 4966.50 & 108.00 & $0.58 a$ & $0.91 \mathrm{a}$ & $1.07 \mathrm{a}$ \\
\hline King & 6.00 & 486.00 & 66.00 & $0.19 a$ & $0.27 \mathrm{a}$ & $0.65 b$ \\
\hline Kiji & 138.00 & 146.00 & 566.00 & $4.45 a$ & $3.84 \mathrm{a}$ & $5.60 a$ \\
\hline Kerosok & 28.00 & 2044.00 & 278.00 & $0.90 a$ & $1.41 \mathrm{a}$ & $2.75 b$ \\
\hline Red & 16.00 & 752.00 & 38.00 & $0.52 \mathrm{a}$ & $0.29 a$ & $0.38 \mathrm{a}$ \\
\hline B. Tiger & 3.00 & 152.00 & 18.00 & $0.10 \mathrm{a}$ & $0.09 a$ & $0.18 \mathrm{a}$ \\
\hline Total & 1126.50 & 24887.50 & 5449.50 & $36.34 a$ & $46.78 \mathrm{~b}$ & $53.96 \mathrm{~b}$ \\
\hline n setting & 31 & 532 & 101 & & & \\
\hline
\end{tabular}

aAngka-angka pada baris yang sama yang diikuti oleh huruf yang sama tidak berbeda nyata pada uji Anova dengan taraf uji 5 \%. Data diolah dari Andang (2011), Hamran (2012), dan data observasi lapangan (2013)

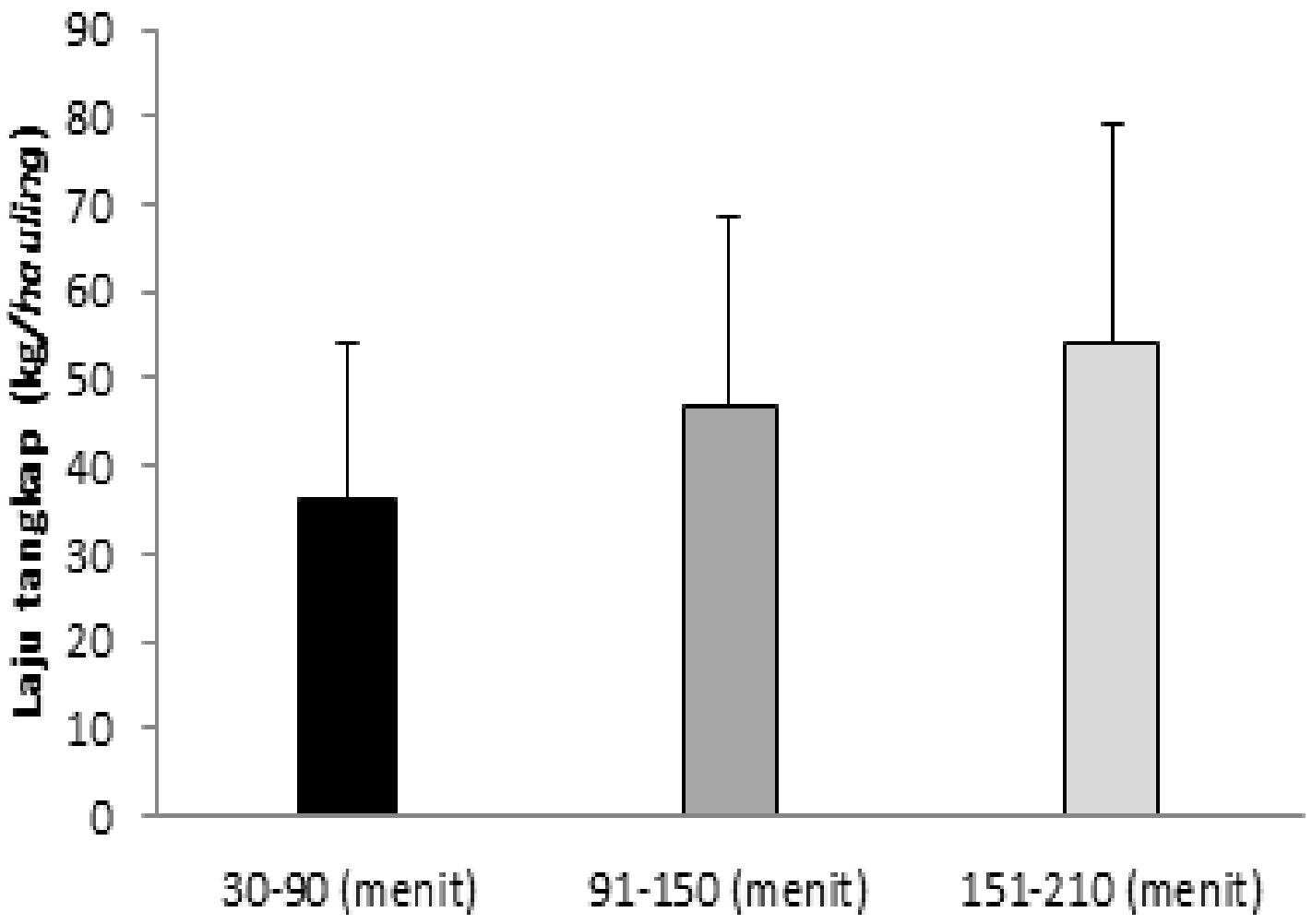

Gambar 3. Hubungan antara lama towing dengan laju tangkap udang 


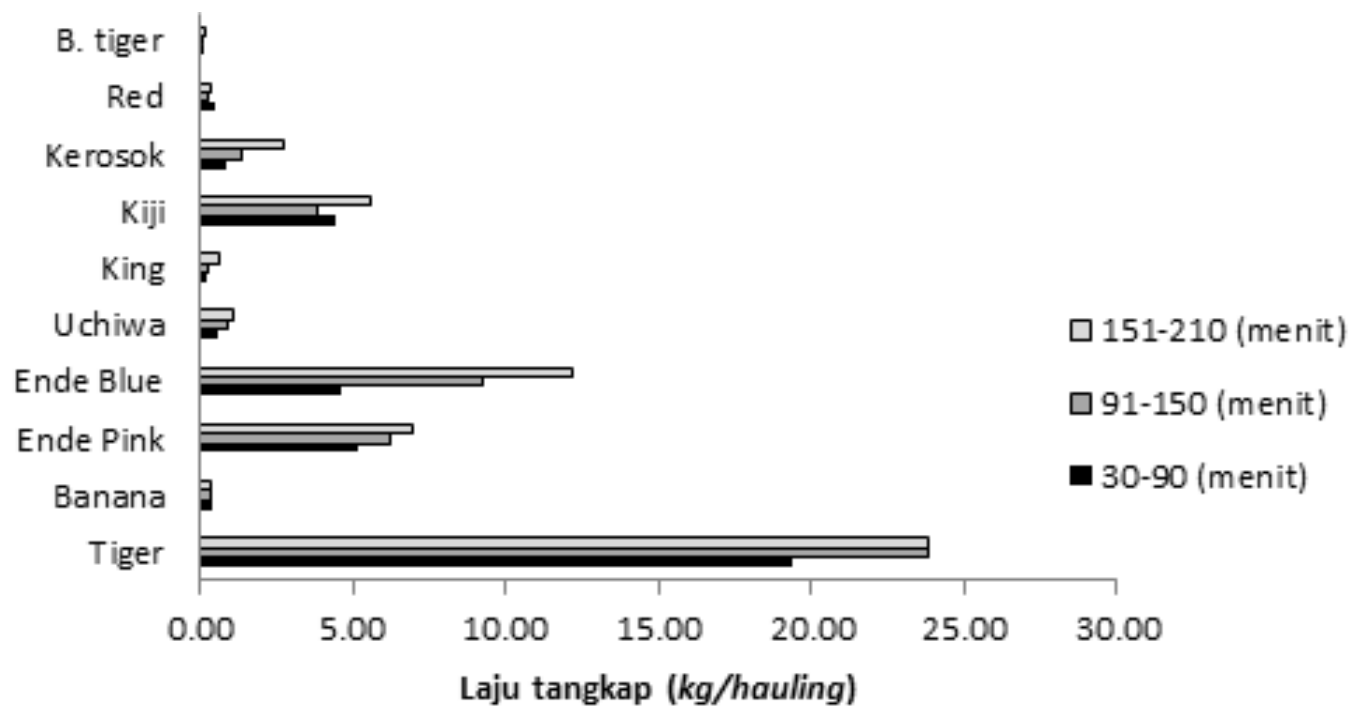

Gambar 4. Laju tangkap per jenis udang berdasarkan lama towing yang berbeda

\section{Pengaruh kecepatan towing (penarikan jaring) terhadap laju tangkap udang}

Kecepatan towing adalah kecepatan kapal ketika melakukan penarikan jaring pada dasar perairan setelah selesai setting. Kecepatan towing pukat udang di Arafura berkisar 2-3.50 knot. Pada penelitian ini kecepatan towing dibuat selang kelas tertentu mulai dari 2.10-2.50, 2.60-3 dan 3.10-3.50 knot. Dibuatnya selang kelas ini dikarenakan penentuan menggunakan GPS yang pada kondisi di lapangan berfluktuasi. Adanya ombak dan juga arus mengakibatkan kecepatan yang ditunjukkan oleh GPS fluktuatif dengan kisaran 0.20 knot diatas maupun dibawah kecepatan sebenarnya.

Laju tangkap udang terendah yakni kisaran 2.10-2.50 knot, sedangkan laju tangkap udang tertinggi pada kisaran 3.103.50 knot. Hasil tangkapan tiap jenis udang berdasarkan perbedaan kecepatan towing dapat dilihat pada Tabel 3.

Jumlah ulangan kecepatan towing 3.10-3.50 knot hanya 9 kali sehingga dianggap kurang representatif. Jika dilihat per jenis udang, ada beberapa jenis udang yang tidak tertangkap dengan kisaran kecepatan ini. Jenis udang yang tidak tertangkap pada kisaran kecepatan 3.103.50 knot adalah udang uchiwa (Thenus orientalis), red (Metapenaeus ensis), dan black tiger (Penaeus monodon). Beberapa jenis udang yang tertangkap pada kisaran 3.10-3.50 knot lebih rendah laju tangkapnya dibanding kisaran kecepatan yang lain seperti jenis udang Ende blue (Metapenaeus endeavouri), kiji (Metapenaeus eboracensis) dan udang kerosok (Parapenaeopsis sculptilis). Hal ini diduga dalam kisaran kecepatan ini rantai pengejut pada pukat udang tidak menyentuh dasar perairan dengan konstan atau melayang diatas substrat. Perbedaan laju tangkap antara kecepatan towing 2.10-2.50 knot dengan 2.50-2.60 knot dapat dilihat pada Gambar 5 .

Analisis yang digunakan dalam menentukan adanya perbedaan antara kecepatan towing 2.10-2.50 dan 2.60-3.00 knot dengan laju tangkap udang adalah uji non parametrik Mann-Whitney karena data tidak terdistribusi normal (Priyatno 2011). Nilai signifikansi pada uji ini adalah 0.005 (lebih kecil dari 0.05), maka HO ditolak. Dapat disimpulkan bahwa ada perbedaan jumlah hasil tangkapan udang pada kecepatan towing yang berbeda. Sesuai dengan hasil penelitian Prisantoso et al. (2010), yakni kecepatan towing berpengaruh terhadap hasil tangkapan jaring arad (mini trawl).

Kecepatan towing akan mempengaruhi bentuk bukaan mulut pukat udang serta posisi pukat udang di dalam air. Kecepatan towing yang berlebih akan menyebabkan jaring melayang diatas substrat. Sedangkan kecepatan towing yang terlalu lambat akan menyebabkan penarikan jaring sangat berat karena rantai pengejut (tickler chain) akan terbenam pada dasar (substrat). Sehingga diharapkan adanya kecepatan optimal sehingga posisi jaring terbuka sempurna dan tickler chain berada pada permukaan substrat yang menyebabkan 
udang tertangkap dengan maksimal. Hasil penelitian ini menunjukkan kecepatan towing dengan laju tangkap lebih tinggi pada pukat udang adalah 2.60-3.00 knot (Gambar 5).

Kecepatan towing juga mempengaruhi luas sapuan jaring dimana semakin luas area sapuan maka probabilitas mendapat hasil tangkapan juga lebih besar. Jaring trawl akan "menyapu" suatu alur tertentu, yang luasnya adalah perkalian antara panjang alur dengan lebar mulut jaring, yang kemudian disebut swept area atau "alur sapuan efektif". Panjang alur sapuan adalah perkalian antara kecepatan towing dengan lama towing. Maka dapat disimpulkan dengan lama towing yang sama tetapi kecepatan towing lebih tinggi, maka luas area sapuan pun akan lebih luas.

Kecepatan towing akan mempengaruhi bentuk bukaan mulut pukat udang serta posisi pukat udang di dalam air. Kecepatan towing yang terlalu tinggi akan menyebabkan jaring melayang diatas substrat. Sedangkan kecepatan towing yang terlalu lambat akan menyebabkan penarikan jaring sangat berat karena rantai pengejut (tickler chain) akan terbenam pada dasar (substrat). Sehingga diharapkan adanya kecepatan optimal posisi jaring terbuka sempurna dan tickler chain tetap menyentuh permukaan substrat yang menyebabkan udang tertangkap dengan maksimal. Hasil penelitian ini menunjukkan kecepatan towing yang efektif untuk pukat udang adalah 2.60-3.00 knot.

Jaring akan terbuka sempurna apabila kecepatan towing optimal dan disesuaikan dengan arah arus perairan (Sasmita 2013). Namun kecepatan towing yang terlalu tinggi juga akan menyebabkan area antar otter board menyempit yang mengakibatkan mengecilnya luasan area dasar perairan yang tersapu. Keragaan jaring dan luas sapuan sangat mempengaruhi keberhasilan penangkapan udang. Rantai pengejut (tickler chain) dengan substrat perairan harus tetap bersinggungan agar dapat merangsang udang untuk melompat dan tersaring ke dalam jaring.

Tabel 3. Hasil tangkapan udang berdasarkan perbedaan kecepatan towing

\begin{tabular}{|c|c|c|c|c|c|c|c|}
\hline \multirow[b]{2}{*}{$\begin{array}{l}\text { Nama } \\
\text { Lokal }\end{array}$} & \multicolumn{3}{|c|}{ Hasil tangkapan (kg/jam) } & \multirow[b]{2}{*}{ Jumlah } & \multicolumn{3}{|c|}{ Laju tangkap (kg/jam) } \\
\hline & $\begin{array}{c}2.1-2.5 \\
\text { (knot) }\end{array}$ & $\begin{array}{c}2.6-3.0 \\
\text { (knot) }\end{array}$ & $\begin{array}{c}3.1- \\
3.5 \\
\text { (knot) }\end{array}$ & & $\begin{array}{c}2.1- \\
2.5 \\
\text { (knot) }\end{array}$ & $\begin{array}{c}2.6-3.0 \\
\text { (knot) }\end{array}$ & $\begin{array}{c}3.1- \\
3.5 \\
\text { (knot) }\end{array}$ \\
\hline Tiger & 359.80 & 1601.20 & 117.50 & 2078.40 & $4.86 a$ & $6.25 b$ & 13.05 \\
\hline Banana & 12.60 & 44.10 & 6.30 & 62.90 & $0.17 \mathrm{a}$ & $0.17 \mathrm{a}$ & 0.70 \\
\hline Ende pink & 94.00 & 317.60 & 11.30 & 422.80 & $1.27 \mathrm{a}$ & $1.24 \mathrm{a}$ & 1.25 \\
\hline Ende blue & 124.00 & 371.00 & 1.20 & 496.20 & $1.68 \mathrm{a}$ & $1.45 \mathrm{a}$ & 0.13 \\
\hline Uchiwa & 23.30 & 56.30 & 0.00 & 79.60 & $0.31 \mathrm{a}$ & $0.22 \mathrm{a}$ & 0.00 \\
\hline King & 11.00 & 13.00 & 4.40 & 28.40 & $0.15 a$ & $0.05 b$ & 0.49 \\
\hline Kiji & 134.00 & 458.10 & 2.10 & 594.20 & $1.81 \mathrm{a}$ & $1.79 a$ & 0.23 \\
\hline Kerosok & 104.00 & 347.50 & 3.20 & 454.60 & $1.40 \mathrm{a}$ & $1.36 \mathrm{a}$ & 0.36 \\
\hline Red & 28.20 & 144.10 & 0.00 & 172.30 & $0.38 a$ & $0.56 a$ & 0.00 \\
\hline B. Tiger & 5.80 & 21.20 & 0.00 & 27.00 & $0.08 \mathrm{a}$ & $0.08 \mathrm{a}$ & 0.00 \\
\hline Total & 896.60 & 3374.07 & 145.81 & 4416.50 & $12.12 \mathrm{a}$ & $13.18 \mathrm{~b}$ & 16.20 \\
\hline $\mathrm{n}$ setting & 74 & 256 & 9 & 339 & & & \\
\hline
\end{tabular}

${ }^{a}$ Angka-angka pada baris yang sama yang diikuti oleh huruf yang sama tidak berbeda nyata pada uji Mann-Whitney dengan taraf uji 5 \%. Data diolah dari Susanto (2011) dan data observasi lapangan (2013) 


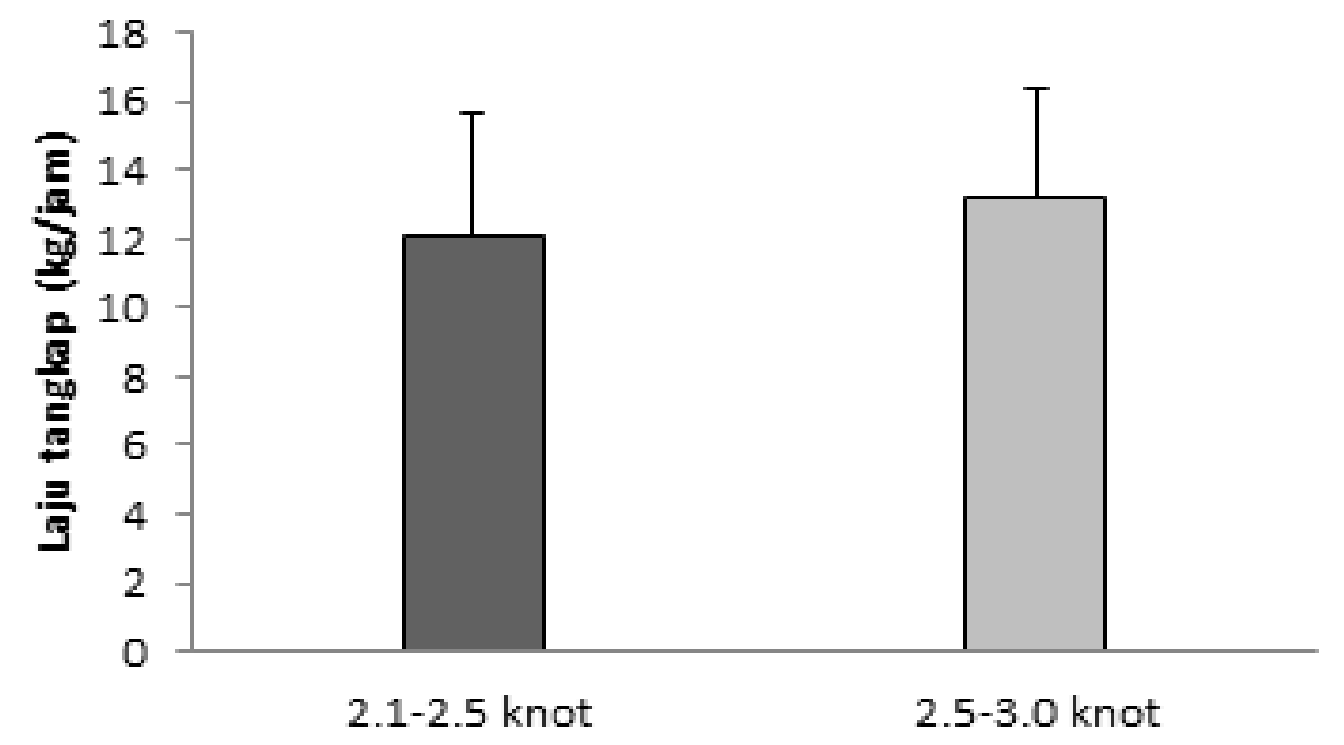

Gambar 5. Laju tangkap udang berdasarkan perbedaan kecepatan towing

\section{KESIMPULAN DAN SARAN}

\section{Kesimpulan}

Kesimpulan yang dapat diambil yaitu waktu penangkapan (siang dan malam hari) berpengaruh terhadap laju tangkap udang, dimana malam hari lebih besar yakni $24.10 \pm 9.60 \mathrm{~kg} / \mathrm{jam}$ dibandingkan siang hari $15.30 \pm 7.60 \mathrm{~kg} / \mathrm{jam}$, lama towing berpengaruh terhadap laju tangkap udang dimana kisaran lama towing yang efektif adalah 91-150 menit dengan laju tangkap (46.78 $\pm 22 \mathrm{~kg} /$ hauling), dan kecepatan towing berpengaruh terhadap laju tangkap udang, dengan kecepatan optimal 2.60-3.00 knot.

\section{Saran}

1. Perusahaan pukat udang tidak terlalu banyak melakukan operasi penangkapan pada siang hari sehingga dapat menghemat bahan bakar

2. Nakhoda kapal melakukan operasi penangkapan dengan lama towing 91150 menit dan kecepatan towing 2.603.00 knot

3. Perlu dilakukan penelitian lanjutan menggunakan kecepatan 3.10-3.50 knot.

\section{DAFTAR PUSTAKA}

Andang. 2011. Studi perbandingan hasil tangkapan antara siang dan malam serta perbedaan lama towing pada Kapal Kurnia 6 milik PT Alfa
Kurnia [KIPA]. Sekolah Tinggi Perikanan: Jakarta.

Bishop JM, Alsaffar AH, Al-Foudari HM, AlJazzaf S. 2008. Diurnal and nocturnal catchability of Kuwait's commercial. Fish Res. 94:58-72.

Dall W, Hill BJ, Rothilsberg PC, Staples DJ. 1990. The Biology of Penaeidae, Advances in Marine Biology. San Diego: Academic Press

Gamito R, Cabral H. 2003. Mortality of brown shrimp discard's from the beam trawl fishery in the Tagus estuary. Elsevier $64: 423-427$

Hamran. 2012. Studi perbandingan hasil tangkapan udang antara siang dan malam hari pada pengoperasian pukat udang di KM. Soerya 81 milik PT. Sinar Abadi Cahaya (SAC). Sekolah Tinggi Perikanan:Jakarta

Mashar A. 2011. Pengelolaan sumberdaya udang manthis berdasarkan informasi biologi di Kuala Tungkal Kabupaten Tanjung Jabung Barat, Jambi [Tesis]. Bogor: Institut Pertanian Bogor

Prisantoso BI, Sadiyah L, Susanto K. 2010. Beberapa faktor produksi yang berpengaruh terhadap hasil tangkapan jaring arad di Pantai Utara Jawa Tengah yang berbasis di Pekalongan. Jurnal Penelitian Perikanan Indonesia 16(2):93-105

Priyatno D. 2011. Buku saku SPSS. Mediakom: Yogyakarta 
Sasmita, Suparman. 2013. Kesesuaian desain dan konstruksi cantrang pada kapal 20 GT untuk peningkatan performa operasional [Disertasi]. Bogor: Institut Pertanian Bogor

Simoes, Christian P, Hose W. 2010. Diel variation in abundance and size of the seabob shrimp Xiphopenaeus kroyeri (Crustacea, Penaeidea) in the Ubatuba region, Southeastern Brazil. Anais da Academia Brasileira: Brazil.

Sudarmono. 2005. Tsunami dan penghijauan kawasan pantai rawan tsunami. Inovasi Online Vol 3(17): Aceh

Susanto E. 2011. Studi pengaruh kecepatan kapal dan kedalaman terhadap hasil tangkapan pukat udang KM Binama 6 milik PT Dwi Bina Utama (DBU) . Sekolah Tinggi Perikanan: Jakarta.

Triharyuni S, Trihargiyatno I. 2012. Model produksi jaring arad di pantai utara Jawa yang berbasis di Pekalongan. Jakarta. Jurnal Penelitian Perikanan Indonesia. 18(4):213-219.

[KKP] Kementerian Kelautan Perikanan. 2011. Statistik Kelautan Perikanan. Jakarta: KKP.

Wieland, Tom Y, Henry T. 2006. Effect of tow duration on catch rate and size composition of northern shrimp (Pandalus borealis) and greenland halibut (Reindhardtius hippoglossaides) in the West Greenland Bottom Trawl survey. Greenland: Elsevier. 